may point out on this spot, in your completed building, a splendid monument of the progress of our medical education, a monument which shall not only prove to the stranger that our physicians are proud of their profession, but one which shall also be a reminder that those who govern within its walls to not forget in their devotion to the science and art of medicine the other duties of citizenship."

It did not perhaps occur to the illustrious speaker how much more is done for the fostering of scientific investigation by some of the "effete monarchies of Europe" than by the great and glorious Government resulting from our free American institutions. $\quad$ P. B. P.

\section{The Rush Monument Fund.}

The attention of the secretaries of county medical societies throughout the United States is called to the resolution adopted at the meeting of the American Medical Association at Newport, "that one member of each county medical society in the Union be appointed to solicit funds for the Rush Monument," and they are requested, at the next meeting of their several societies, to ask that such a member be designated for this purpose, and to send his name and address either to the undersigned, or to Medical Director Albert L. Gihon, U.S. N., Chairman of the Rush Monument Committee, U. S. Naval Hospital, Brooklyn, N. Y.

Ail subscriptions, however, should be remitted directly to the Treasurer of the Rush Monument Committee, Dr. DeWitt C. Patterson, 9I9 T street, N.W., Washington, D. C.

William B. Atrinson, Permanent Secretary A. M. A. I 400 Pine-street, Philadelphia, Pa.

\section{Unusual Length of Funis.}

To the Editor:-I wish to report a case which, although by no means unique, is, nevertheless, not without interest. I recently attended a young woman, 22 years of age, in her first confinement. She was of slight figure and weighed less than Ioo pounds. The child (which was found to weigh $91 / 2$ pounds) was born in a condition of asphyxia livida, a condition produced by reason of a coiling of the funis around the neck. There were five of these coils, drawn very tight, notwithstanding which circumstance there was an abundance of slack left. The child was resuscitated without much difficulty, and in half an hour the placenta was delivered by Crede's method. The latter was of unusual size, being far larger than any other placenta I ever saw, although, as ustial in such cases, it was by no means proportionately thick. When expelled it was rolled up like a scroll. Following the third stage of labor there was a very considerable flow of blood, although the uterus contracted fairly weil. This, however, soon stopped after the removal of a large quantity of clots from the vagina and cervical canal. There was a very apparent relation between the area of the placental insertion and the amount of blood lost. The cord measured 48 inches in length and was not especially attenuated. This length, although very unusual, has no doubt often been surpassed. Schneider recorded a funis 120 inches in length which made six turns around the child's neck; Bandelocque reported an instance in which a cord of 59 inches had seven coils ; Mme. Waldwogel mentions a case in which there were eight coils.

Yours truly, Junius C. Hoag, M.D.

Chicago, October 9, I889.

\section{BOOK REVIEWS.}

Catalogue of Sharp \& Smith, Importers, MANUFACTURERS, WhOLESALE AND RETaII, DEAL,ERS IN SURGICAI INSTRUMEN'TS AND DEFORMity Apparatus. Chicago, i889; pp. 973.

This is a voluminous and excellent catalogue. It is very complete and well illustrated. Its arrangement is convenient. It is to be commended among trade publications.

The Physician's Leisure Library, Series IV. SyPHILIS OF THE NeRvous SYSTEM, by H. C. Wood, M.D., LL.D.; pp. I35. I889. Detroit : George S. Davis.

The medical public is always glad to hear from one of its most honored exponents in this country, Dr. H. C. Wood, and if, therefore, an interest be awakened by the announcement of a new brochure bearing the above title, we can assure our readers that they will find no cause for disappointment in a perusal of the particular volume in question. There are few physicians who are in a position to speak more authoritatively upon this subject than Dr. Wood, who has reached the conclusions herein set forth from a study of 2,000 cases of nervous disorders associated with syphilis. Among the many points of interest made by the author is this one: That there is a syphilitic insanity which exists without obvious meningeal disease, and is capable of being cured by antisyphilitic treatment, in support of which view a table of illustrative cases is given with regard to the method of antisyphilitic treatment by the hypodermic injection of the insoluble salts of mercury, a method which has been greatly praised by some European physicians. The 